\title{
The 21st Century Skills in Online Multiliteracies Project Approach (eMULPA): Learners' Reflections on their Knowledge Processes
}

\author{
Suraini Mohd Ali* \\ Haliza Harun \\ Norhaili Massari \\ Fariza Puteh-Behak \\ Ramiaida Darmi \\ Normazla Ahmad Mahir \\ Suzana Selamat \\ Yurni Emilia Abd. Hamid \\ Faculty of Major Language Studies, Universiti Sains Islam Malaysia \\ Bandar Baru Nilai, 71800 Negeri Sembilan, Malaysia \\ *Email: suraini@usim.edu.my
}

\section{Doi:10.5901/mjss.2017.v8n1p252}

\section{Abstract}

There is a misconception that 21 st century education is all about using the right online tools. However, the premise of 21 st century education requires the integration of relevant content, skills and instructional support to enhance knowledge processes in line with the requirement of 21st century learning to arrive at meaningful learning experience and not merely the use of online tools. To enhance the integration, an Online Multiliteracies Project Approach (eMULPA) framework is designed by incorporating teachers' presence, online tools, learning materials, collaborative efforts while fulfilling the syllabus requirement so that the interconnectedness in these elements would give learners a learning experince that is worthwhile and meaningful. The framework which encompases the knowledge processes: exploration, contexualization, investigation, delibration and consolidation is expected to assist learners to have meaningful learning. This paper focuses on the learners'experiences while undergoing the knowledge processes in eMULPA. Data collection tools were interviews, teaching documents and learners' reflective journals. For this paper, only data from learners' reflective journal were drawn, coded for themes and explicated because reflective journal is one of the reliable means to gather information on the metacognitive processes undergone by learners. The preliminary findings demonstrated learners' have undergone meaningful learning experiences through the eMULPA knowledge processes higlighted above. Thus, the implementation of eMULPA is expected to assist learners to acquire the 21 st century skills.

Keywords: 21st Century Skills, Online Multiliteracies Project Approach (eMULPA), Knowledge Processes

\section{Introduction}

Graduate employability issue has been actively discussed in Malaysia in which 161, 000 graduates were reported to be unemployed (Bernama, 2015). A number of studies raised the issue of unemployment among Malaysian graduates who lacked employability skills and 21st century skills to be at par with the current globalization and technological era (Hairuszila, et al. 2009; Morshidi, et al., 2012). In the 21 ${ }^{\text {st }}$ century, with the globalization and advent of technologies, education has taken a new leap in its mission to produce graduates who have undergone a meaningful learning experience and are highly productive, effective communicators, inventive thinkers and masters of technology. Since online learning in tertiary education is taking up a central stage, we argue that having a repository by compiling online materials and getting the learners to work on them are not sufficient to give the learners a meanigful learning experience which are interconnected and resembles real world. The current study embarks on an Online Multiliteracies Project Learning Approach (e-MULPA) that combines the multiliteracies approach (Fariza Puteh-Behak, 2013), task-based 
language teaching (Ramiaida Darmi, 2013) and project-based learning as a new teaching and learning approach which incorporate elements of online learning and softs skills.

\section{Literature Review}

The focus of education should now be put on the cultivation of knowledge process and 21st century skills such as communicational skills, technological skills, creative and critical thinking skills as well as collaborative learning skills in our classrooms. As such, a learning model is needed as a framework of reference for teachers and learners to incorporate learning using online tools, $21^{\text {st }}$ century knowledge process as well as the authenticity of classroom learning to generate multiliterate graduates.

Hence, online Multiliteracies Project Approach (e-MULPA) is being initiated. This novel teaching and learning approach focuses on the online multiliteracies project approach that would combines the authenticity of classroom learning and learning using online tools. E-MULPA combines three established teaching approaches which are: the multiliteracies pedagogy (Fariza Puteh-Behak, 2013, The New London Group, 2000), task-based language teaching (Ellis, 2009; Ramiaida Darmi, 2013), and project-based learning.

Traditionally, learning is made up of separate and disconnected pieces, causing learners to have a disrupted view in the subject matter. Through e-MULPA, learning is made more meaningful as all lessons are interconnected and arranged to involve the learners in a meaningful learning experience. In being part of a meaningful learning experience, the learner will have a better understanding of the subject matter and have the opportunity to practice $21^{\text {st }}$ century skills. It is hoped that these learners will be able to polish their employability competence.

This module is a first of its kind in providing references for English language lecturers to incorporate online tools, $21^{\text {st }}$ century skills and the authenticity of classroom learning in order to generate multiliterate graduates for the $21^{\text {st }}$ century workforce. This module is comprehensive as it will guide educators in designing a multiliteracies project approach for their own learning context. The module will also outline how to interconnect the lessons to make learning more meaningful.

e-MULPA module is beneficial as it assists lecturers in producing unique on-line lessons aimed at generating skilled university graduates who possess $21^{\text {st }}$ century skills and are able to meet the demand of modern employment.

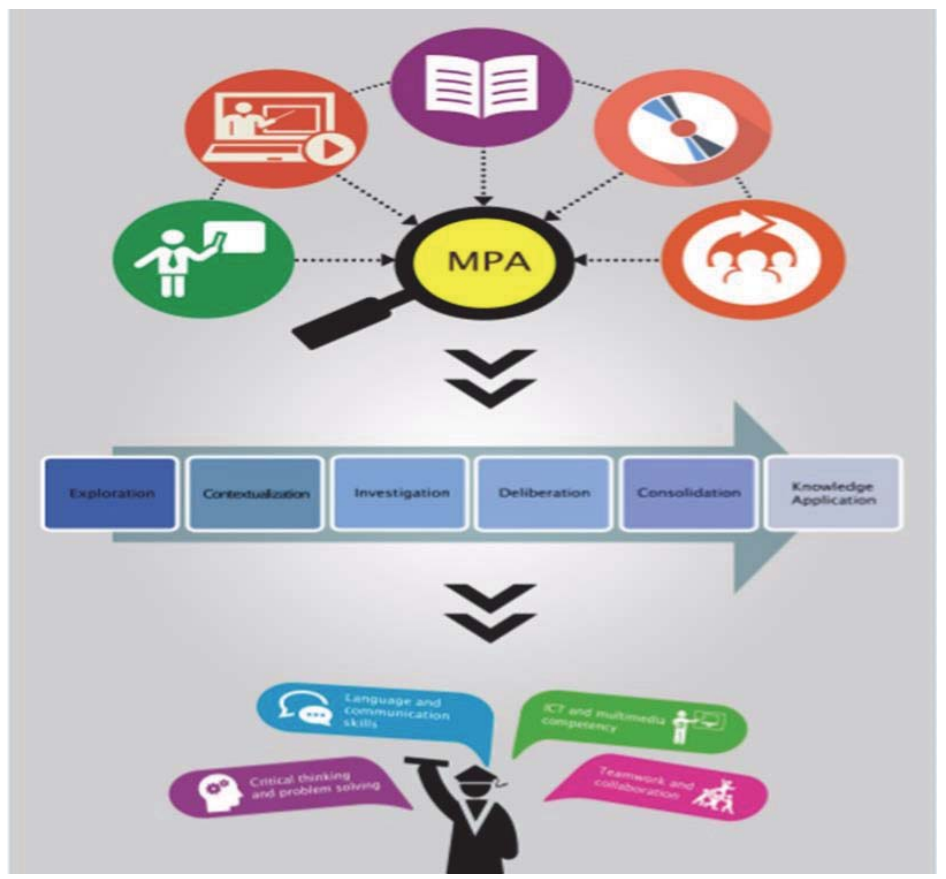

Figure 1: e-MULPA Framework 


\title{
3. Methodology
}

This study adopts a qualitative research paradigm. Data were collected through interviews, teaching documents and learners' reflective journals. For this paper, data from learners' reflective journal were drawn because reflective journal is one of the reliable means to gather information on the metacognitive processes undergone by learners. In eMULPA, reflective journals are used to describe the learners' experience in the process of learning. Through the journal writing process, students indirectly become "more aware not only of what they learn, but also how they learn" (Voss, 1988). Journals provide extremely useful insights into how students cope with the learning experience-- how they study, how they handle materials, how their understanding changes through the course and how they take responsibility for their own learning (Park, 2003). The data from the reflective journal were stored in excel files, coded for themes and explicated using the knowledge processes in EMULPA: exploration, contexualization, investigation, delibration and consolidation.

The research participants were a group of $48 \mathrm{ESL}$ (English as a second language) undergraduates whom were taking BIA 2012 (English for Communicative Purposes) during their first semester at the university. Specifically, it is an intermediate course that aims to enhance learners with the appropriate language skills, grammar and vocabulary required at the varsity level. The teaching and learning process in this course is focused on the application of various skills through language learning activities; both in and outside classroom. Assessments are continuous and geared towards developing learners to achieve a satisfactory level in the language.

\section{Findings \& Discussion}

Findings indicated that e-MULPA has positively initiated and facilitate learners' knowledge processes in transforming learners existing knowledge and skills to meet the much needed $21^{\text {st }}$ century learning skills. As this online multiliteracies project approach embodies three established teaching approaches, that are multiliteracies approach, task based language teaching approach and project based learning approach, the strength of this approach is evident the different stages of knowledge processes that learners individually undergo and collaboratively participated.

Subsequently, the findings of this paper will focus on how the stages in the knowledge processes has provided meaningful learning experiences for learners and hence further facilitate and support their knowledge and skills in the effort to generate multiliterate graduates to meet the demand of the $21^{\text {st }}$ century knowledge and skills.

\subsection{Exploration stage}

In the exploration stage in eMULPA, the learners were asked to form small focus groups and identify significant issues in their community. In this stage, learners were expected to search for relevant issues and exercise the relevant skills to complete the project given to them. Exploration is a concept that deals with the use of hands-on manipulatives and learner inquiry in collaborative nature with active engagement to search for new knowledge in the learning process. The learners' reflections can be categorized into two pertinent themes: the use of hands-on manipulatives and search for new knowledge.

A number of learners' reflections dealt with the interest and gains related to IT skills for the former category. When the learners were in the exploration stage, they mostly relied on hands- on manipulatives specifically online tools to start off their project. Some of the excerpts on learners' interest in using the online tools are:

\author{
I like learning about research survey using Google Form because before this I have never use it (BS 3). \\ I really like the video activity because it is so interesting and I never use it before...it also gives training to produce a \\ good video by me (BS 16). \\ The learners also reflected on the gains of the online tools: \\ When I did the Google Form survey, I gained more experience through research (BS 18). \\ Video presentation also improves my video editing skills using many online apps (BS 23)
}

In light of the learners' reflections on interest and gains in IT skills in the exploration stage, the 21st century skills: creativity and innovation skills, were evident. Wegerif \& Dawes (2004) asserts that creativity is a pertinent skill that can and ought to be fostered. In an analysis, Loveless (2002) talks about the connection between technology, learning and creativity, which highlighted how technology allowed individuals to produce high quality work in a range of media that provided platforms for creativity to take place. The misconception that creativity and innovation skills are only for artistictypes and geniuses; creativity is something one is born with or without (Trilling \& Fadel, 2009), has led to the neglect of these skills to be nurtured. Trilling \& Fadel (2009) further argue that creativity can be nurtured by teaching staff and 
learning environments that empower questioning, openness to new ideas, and learning in the process of trial and error. Creativity and innovation skills (Wegerif \& Dawes, 2004) can be developed, like other skills, with practice and perseverance.

Thus, the learners have shown through their reflections that their interest and the gains in using and selecting appropriate online tools which were within their accessibility (hands-on manupulatives; creativity and innovation skills), have made them learn part of their project at the onset stage without being too dependent on the teachers. In other words, they have demonstrated their grasp of the 21st century skills namely creativity and innovative skills in the exploration stage.

The second theme in the exploration stage is learning new things. The reflection from learners clearly portrayed that the quest for new knowledge and skills started at the beginning of the eMULPA project. The learners responses under the second theme (Learning new things) can be categorized into: new experiences and personalized preference.

Here are some of the excerpts on learners' reflection on new experiences:

I like learning about research survey using Google Form because before this I have never use it (BS6)

First of all it give me a new experience on the available tools for video presentation which I never do it before (BS 5)

During our video shooting, that's the first time l'm talking like a TV personality (BS 9).

I like it. Because I can learn new thing like how to create documentary and the process. And I like to create and would like to suggest all people to create video or anything related to media (BS 12)

The learners also did highlight about their preferences on using certain tools over the other since they had the opportunity to self-select the tools during the exploration stage:

First, I like it because I dont need to talk a lot , just use visuals ( BS 10)

Apart from that, through video production, I get to learn the way to project my voice effectively when speaking in the video. I also learnt ways to post video documentary on the internet (BS 24)

\subsection{Contextualization stage}

The second knowledge process that learners went through is contextualization which means the connection between the subject matter with the competencies required (National Governors' Association \& Council of Chief State School Officers, 2010).

In eMULPA the learners were given the guide by the teacher to select the issues they were interested in for their project in which the learners worked collaboratively to link the selected issue with real word setting and community. In the reflections, the learners highlighted that the process has enhanced their existing knowledge in terms of their personal interest, current proficiency level and IT skills. Some of their reflections are:

I like producing video because I have a deep interest on video editing and such. Thus, this experience help improve my video producing skills for future use (BS 3)..

In my opinion, learning approach like this can help low proficient students to excel in the English language subject (BS 15).

It help me to gain more IT knowledge (BS 22)

Therefore, learners experiences in this stage, has demonstrated that they learnt the 21st century skills such as the critical thinking, communication and ICT skills which are the aims of eMULPA, in the process.

\subsection{Investigation stage}

The investigation stage involved in the knowledge processes found in e-Mulpa encompasses the opportunity for learners to be engaged in collaborative learning to investigate not only the problems reflected in the nontrivial issue identified in the exploration stage, but also how the tools are to be effectively used in presenting the particular issue.

At this stage, learners were expected to pursue each aspect of the inquiry by generating and refining the questions of the issue identified within the community that they are in; in this case issues relating to the undergraduates studying at a particular university. These points are evidenced in the following excerpts:

Learning experience through research helps to gain knowledge about something new (BS23)

Secondly, I like the learning experience through research because I and my team had a very good cooperation (BS10) 
Besides that, they were also required to consider the relevant research tools required to capture and extract specific information required to the issue identified. This includes the use of online survey tools such as Google forms to gain in-depth understanding of the problem in question.

Yes, I do the learning experience through research and survey (BS1)

I like learning about research survey using Google Form because before this I have never use it (BS3)

When I did the Google Form survey, I gained more experience through research (BS18)

Investigation on using the technology as a tool to present the results of the deliberated solutions identified for the issue in question also is also evident at this stage. While the exploration stage involves learners using and selecting the appropriate online tools within their accessibility at the onset stage of their learning, the investigation stage provides learners the opportunity to identify and plan how to use these tools effectively in succinctly presenting the solutions emanating from the issue identified. Among the tools selected include the use of recorded video and animation softwares available on the internet such as Prezi, PowToon, Movie Moment, and even Movie Maker to convey their ideas regarding the issue in question. The following excerpts are some of the examples of learners experience using these online tools in their learning processes:

Of course.In producing the video, I gained a lot of information regarding this topic and issue discussed. In fact, the activity enhanced my knowledge about a certain issue (BS17)

Yes, I like the learning experience through research/survey and producing video presentations because can expose me on how to create good video, to communicate with others (BS18)

According to Sheppard (1998), such learning approach encourages learners' critical thinking skills as they are demanded to define and identify not only the problems at hand, but also make predictions and debate ideas by asking and refining the relevant questions needed (Blumenfiled et al., 1991).

It is noteworthy to highlight that these findings also suggest that e-Mulpa was able to initiate and facilitate learners existing knowledge and skills and hence transformed them to new social contexts in which new knowledge and skills that are crucially demanded for the $21^{\text {st }}$ century can be achieved. Moreover, other findings gained from this study also showed that learning enjoyed the new experience and skills learnt and acquired whilst completing the e-Mulpa project.

Yes, I do the learning experience through research and survey. And producing video presentation because it is challenging to me (BS1)

In addition, it will not be boring and was very interesting learning (BS7)

Yes, of course. During research and producing video, I have enjoy myself very much (BS9)

And I think this type of learning is enjoyable and interesting (BS11)

Additionally, as issues dealt during the learning process consist of those that are related to the problems faced in a real and actual context, learners also had the opportunities to use the target language learnt in an authentic contexts. In doing so, the language learning process can progress positively as learners' natural language learning capacity is nurtured (Ellis, 2009).

This experience makes me really really loves toward English subjects, and also improving my self confidence to speak English (BS6)

This project makes me enjoy and make me improve to speak English (BS13)

Importantly, this positive experience stated above by the learners involved, is crucial not only to create a conducive learning environment, but to provide learners with the opportunities to participate effectively in a variety of formal situations to generate multiliterate graduates to meet the challenges of the $21^{\text {st }}$ century education.

\subsection{Deliberation stage}

The deliberation stage that is involved in e-MULPA consists of learners' collaboratively collecting and analysing data, drawing conclusions, communicating their ideas and findings to others as well as creating the relevant artefacts. Subsequently it provides the learners with the 'knowing and doing' opportunities in their learning processes where they are not only required to acquire the relevant knowledge embedded in their curriculum, but also to apply what they know to solve the issue identified (Markham, 2011). This is evidently shown in the following excerpts: 
lot about how to produce the videos, we collect information and keep changing the information. I like it very much (BS10)

I really like the video activity because it is so interesting and it also gives training to produce a good video (BS16)

I like producing video with my team. My team has many ideas. Finally we get second in producing video. We are very happy (BS10)

It is also important also to highlight as learners work together in their individual groups assigned, such tasks encourage them to participate meaningfully in the decision making process.

Second, I learn on how to commiunicate with other people to get information and cooperate with them (BS 2)

Work in group is also give a new ways to communicate(BS 5)

First the reason is the cooperation of my group. They give full cooperation and attention during complete our survey task (BS 9)

Subsequently, such collaborative learning experience facilitated learners becoming critical thinkers hence further support their transformed learning experience as exhibited through their e-MULPA projects (Figure 2).

From the video activity, I get to learn how to speak confidently, and do research on current issues (B17)

Yes, I like the learning experience through research/survey and producing video presentations because I can explore and gain more knowledge about how to make the good video presentations (BS11)

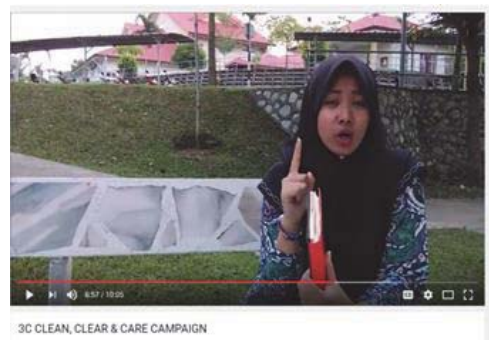

Figure 2: Learners Video Project (3C-Clean, Clear and Care Campaign)

\subsection{Consolidation stage}

Upon going through the five stages, learners arrived to the Consolidation stage where there are more face-to-face interactions between the Teacher-Learners and among the learners themselves, as they presented their work and video and come to assess their progress as a group. These interactions were more flexible especially for online interactions involving:

1. Learners discussion sessions regarding the presentations' topics and ideas

2. Learners' consolidation of information as they identify, compare, and analyze information from a number of textual sources; they also need to synthesize information from various sources to solve problems and perform tasks

Learners were encouraged to express and justify their opinions about important issues or personal preferences, with support from personal knowledge or experience or from other sources. Learners could also reflect on their progress as a reader and writer and make use of appropriate academic resources substantially well. Two significant elements that were developed in these processes were the learners' public speaking skills and their confidence levels as articulated through their comments in the reflective journals:

Enhanced Public Speaking Skills :

Thirdly, I like it because I experience like on actress. Speaking in front of camera, talking formally, talk about learner issue. That's really joyful (BS10)

Apart from that, by producing [the] video, I have more courage to speak in front of the public. It also eliminates the feeling of shyness/ self-inhibition in me (BS13) 
Improve my self-confidence to speak English (BS6)

I feel really great when I complete this task (BS17)

My confidence has also increased (BS 24)

Also, learners viewed their experience in a positive light, as they become more engaged in the learning process and are more aware of how they are learning. These are evident through the learners' responses:

\author{
I gained a lot of experience through this project. (BS14) \\ I also gained new knowledge in producing the video (BS 17) \\ Learning experience through research helps to gain knowledge about something new (BS 23)
}

Throughout the learners' experience undergoing eMULPA, learners also commented that their teamwork improved in spite of the challenges that EMULPA brought to them. They were able to critically evaluate their work process and quality, thus developing critical practical knowledge in order to fulfill each task. Learners reported substantial knowledge and skills growth and also transformations to their thinking and attitude to learning which runs well with their expectations of what learning at the university level is like. Subsequently, their journey through eMULPA has prepared the learners with the critical skills needed for them to function in the 21st. Century learning and workplace, as it directly addressed integral aspects linked to multiliterate graduates.

\title{
5. Conclusion
}

Overall, evidence from the learners' reflective journals show that eMULPA has allowed for a meaningful learning experience to take place, by interconnecting all the critical elements for successful learning: teachers' presence, online tools, learning materials, collaborative efforts and the syllabus. eMULPA has provided the space for them to be in charge of their learning, to be more active and more engaged in learning. These newly-acquired learning process, experiences, perspectives and skills matched the learners' expectations of what a tertiary education stands for and transformed the learners into the aspired multiliterate graduates equipped with the 21st. Century skills needed for them to function effectively when they enter the workforce.

\section{Acknowledgement}

This work was supported by the Malaysian Ministry of Education under FRGS Grant Nos: USIM/FRGS/FBU/32/51313.

\section{References}

Blumenfield P.C. et al. (1991). Motivating project based learning : sustaining the doing, supporting the learning. Educational Psychologist. 26, p. 369-398.

Dewey, J. (1929). My pedagogic creed. Journal of National Education Association. 18 (3), p. 291-295.

Ellis, R (2009). Taks-based language teaching: sorting out the misunderstandings. International Journal of Applied Lingusitics. 19 (3), p.221-246.

Fariza Puteh-Behak (2013) Using multiliteracies approach in a Malaysian University:a participatory action research project. Doctoral Dissertation. University of Southern Queensland, Toowoomba Australia.

Hairuszila, I., Hazadiah, M., \& Normah,A. (2009). Challenges in the integration of soft skills in teaching technical courses: Lecturer's perspectives. Asian Journal of University Education, 5 (2), 67-81.

Markham, T.(2011). Project Based Learning. Teacher Librarian. 39(2), p. 38-42.

Morshidi, S., Heng, C. L., Munir, S., Shukran, A. R., Seri Rahayu, A.K., \& Singh, J. K. N. (2012). Employability of graduates in Malaysia. Graduate employability in Asia, p.24-37. Bangkok : UNESCO Bangkok.

National Governors' Association \& Council of Chief State School Officers (2010). http://ccrc.tc.columbia.edu/media/k2 /attachments/facilitating-learning-contextualization-working-paper.pdf

Park, C. (2003). Engaging students in the learning process. The Journal of Geography in Higher Education, 27 (2,) p. 183-199.

Ramiaida Darmi (2013). Exploring teacher-learner perceptions of first language use and tasks and their relationships to task types and task difficulties in a Malaysian tertiery context. Working projects. La Trobe University, Melbourne, Australia.

Shepherd, H. G. (1998). The probe method: A problem-based learning model's effect on critical thinking skills of fourth- and fifth-grade social studies students. Dissertation Abstracts International, Section A: Humanities and Social Sciences. 59 (3-A), p. 0779.

Trilling, B. \& Fadel, C. (2009). Twenty First Century Skills: Learning for Life in Our Times. San Francisco: Jossey-Bass.

Voss, M.M. (1988). The light at the end of the journal: a teacher learns about learning. Language Arts, 65(7), p. 669-674.

Wegerif, R. \& Dawes, L. (2004). Thinking and Learning with ICT: Raising Acievement in Primary Classrooms. London: Routledge. 